\title{
Costos de producción de productos agroecológicos, en productores familiares de pequeña escala, de la Feria Agroecológica UNIMINUTO, Colombia
}

Production costs of agroecological products, in small family producers scale of the Agroecological Fair UNIMINUTO, Colombia

Custos de produção de produtos agroecológicos, em pequenos produtores familiares escala da Feira Agroecológica UNIMINUTO, Colombia

\section{Adriana María Chaparro-Africano ${ }^{1}$ Nayeth Salazar Soto ${ }^{2}$}

Recibido: marzo 11del 2019

Aprobado: noviembre 20 del 2019 Disponible en línea: enero 31 del 2020

Cómo citar este artículo:

Chaparro-Africano, A. M. y Salazar Soto, N. (2020). Costos de producción de productos agroecológicos, en productores familiares de pequeña escala, de la Feria Agroecológica UNIMINUTO, Colombia. Cooperativismo \& Desarrollo, 28(116), 1-31. doi: https://doi.org/10.16925/2382-4220.2020.01.07

Artículo de investigación. https://doi.org/10.16925/2382-4220.2020.01.07

1 Médico Veterinario Universidad Nacional de Colombia 2001, Máster en Agroecología Universidad de Córdoba España 2011, Doctorado en Recursos naturales y gestión sostenible Universidad de Córdoba España 2014. Profesora Ingeniería agroecológica Corporación Universitaria Minuto de Dios. Bogotá Colombia

Correo electrónico: achaparro@uniminuto.edu.co

ORCID: https://orcid.org/0000-0001-9124-3005

2 Contadora pública en proceso de formación Corporación Universitaria Minuto de Dios. Bogotá Colombia

Correo electrónico: nsalazarsot@uniminuto.edu.co 


\title{
Resumen
}

Esta investigación aplicada se desarrolló entre 2017 y 2018 con productores de la Feria Agroecológica UNIMINUTO - FAU en Bogotá. Su objetivo fue analizar los costos de producción de bienes agroecológicos obtenidos por productores familiares de pequeña escala, debido a que las ventas en este espacio no han incrementado significativamente a través de su historia (2012 a 2018), y debido al reclamo permanente de los compradores por los altos precios de venta. Para alcanzar el objetivo se seleccionó una metodología de cálculo de costos (Chaparro, 2017), que se adaptó y se aplicó a 33 productos -frescos, procesados, aseo y plantas ornamentales- de 15 productores. Luego de recolectar la información en un formato de costos, se realizó un análisis de costos de producción por producto, que luego se comparó con la literatura disponible -21 sistemas de producción documentados-. Como resultados, de los 15 productores, el $80 \%$ no lleva registros de producción, el 26 \% no conoce sus costos, y el $37 \%$ no tiene registros de venta. La producción se encuentra en un rango de $16,96 \mathrm{~kg}$ a $14.516 \mathrm{~kg}$, para periodos de dos meses a un año, siendo de muy baja escala frente a los estudios comparados. Los 15 productores generan de 1 a 23 empleos, siendo mayor la generación de empleo frente a los estudios comparados. Los costos unitarios de producción son más altos en un $62 \%$ de los productos evaluados, frente a los estudios comparados. En el $60 \%$ de 30 productos el principal costo de producción son los insumos y en el 26,6 \% es la mano de obra. Para el $76,6 \%$ de 30 productos se obtuvo utilidad. Siete productores de 14 pueden mantenerse en su actividad económica gracias a sus utilidades. Las principales limitantes de los productores agroecológicos de la FAU para tener costos de producción más bajos son la escala de producción, y en el caso de los productos procesados, el costo de los insumos agroecológicos.

Palabras claves: registros de producción, costos unitarios de producción, escalas de producción, estructura de los costos de producción, utilidades o pérdidas.

Q00 Economía de los recursos agrícolas y naturales; Economía ambiental y ecológica: general

D24 Producción; Costo; Capital; Capital, Factor Total y Productividad Multifactorial; Capacidad

Q57 Economía ecológica: servicios ecosistémicos; Conservación de la Biodiversidad; Bioeconomía; Ecologia industria

\begin{abstract}
This applied research was carried out between 2017 and 2018 with producers from the Agroecological Fair UNIMINUTO - FAU in Bogotá. Its objective was to analyze the production costs of agro-ecological goods obtained by small-scale family producers, because sales in this space have not significantly increased throughout its history (2012 to 2018), and due to the permanent claim of buyers because of the high sale prices. To achieve the objective, a calculation of costs methodology was selected (Chaparro, 2017), which was adapted and applied to 33 products - fresh, processed, cleaning and ornamental plants - from 15 producers. After collecting the information in a costs form, an analysis was performed of production costs by product, which was then compared with the available literature -21 documented production systems. As a result, of the 15 producers, $80 \%$ do not keep production records, $26 \%$ do not know their costs, and $37 \%$ have no sales records. Production is located in a range of $16.96 \mathrm{~kg}$ to $14,516 \mathrm{~kg}$, for periods of two months to one year, being of very low scale compared to comparative studies. The 15 producers employed from 1 to 23 jobs, with the generation of jobs being greater than in comparative studies. Unit production costs are $62 \%$ higher than the products evaluated in comparative studies. In $60 \%$ of 30 products the main cost production are inputs and $26.6 \%$ is labor. $76.6 \%$ of 30 products were considered useful. Seven producers out of 14 can maintain their economic activity thanks to their profits. The main constraints of FAU agroecological producers to have lower production costs they are the scale of production, and in the case of processed products, the cost of agro-ecological inputs.
\end{abstract}

Key words: production records, unit costs of production, scales of production, structure of production costs, profits or losses. 
Q00 Economics of agricultural and natural resources; Environmental and ecological economics: general

D24 Production; Cost; Capital; Capital, Total Factor and Multifactor Productivity; Capacity

Q57 Ecological economy: ecosystem services; Conservation of Biodiversity; Bioeconomy; Ecology industry

\section{Resumo}

Esta pesquisa aplicada foi realizada entre 2017 e 2018 com produtores da Feira Agroecológica UNIMINUTO - FAU em Bogotá. Seu objetivo era analisar os custos de produção de bens agroecológicos obtidos por pequenos produtores familiares, porque as vendas nesse espaço não aumentou significativamente ao longo de sua história (2012 a 2018) e devido à reivindicação permanente de compradores por causa dos altos preços de venda. Para atingir o objetivo, foi selecionada uma metodologia de cálculo de custos (Chaparro, 2017), adaptado e aplicado a 33 produtos - frescos, processados, limpeza e instalações ornamental - de 15 produtores. Após coletar as informações em um formato de custo, foram realizadas uma análise dos custos de produção por produto, que foi comparada com a literatura disponível - 21 sistemas de produção documentados. Como resultado, dos 15 produtores, $80 \%$ não mantêm registros produção, $26 \%$ não conhecem seus custos e $37 \%$ não possuem registro de vendas. A produção está localizada na faixa de 16,96 kg a $14.516 \mathrm{~kg}$, por períodos de dois meses a um ano, sendo de escala muito baixa em comparação com para estudos comparativos. Os 15 produtores geram de 1 a 23 empregos, a geração de emprego versus estudos comparativos. Os custos unitários de produção são $62 \%$ superiores aos os produtos avaliados, comparados aos estudos comparativos. Em $60 \%$ de 30 produtos, o principal custo produção são insumos e $26,6 \%$ é mão-de-obra. Para $76,6 \%$ de 30 produtos foram obtidos utilitário. Sete em cada 14 produtores podem manter sua atividade econômica graças aos seus lucros. As principais restrições dos produtores agroecológicos da FAU de ter custos de produção mais baixos eles são a escala de produção e, no caso de produtos processados, o custo de insumos agroecológicos.

Palavras-chave: registros de produção, custos unitários de produção, escalas de produção, estrutura de custos de produção, lucros ou perdas.

Q00 Economia de recursos agrícolas e naturais; Economia ambiental e ecológica: geral

Produção D24; Custo; Capital; Capital, fator total e produtividade multifatorial; Capacidade

Q57 Economia ecológica: serviços ecossistêmicos; Conservação da Biodiversidade; Bioeconomia; Ecologia indústria

\section{Introducción}

FAO (2018) Aguilar (2017), Martínez-Torres y Rosset (2014), entre otros, aseguran que los costos de producción de los productos agroecológicos son menores debido al menor uso de insumos de síntesis y a pesar del mayor requerimiento de mano de obra. Pero a su vez, los costos de producción de la agricultura convencional son mayores (Altieri, 2009). Esta situación daría como resultado precios de venta de productos agroecológicos iguales o menores a los productos convencionales, lo que no ocurre en la Feria Agroecológica UNIMINUTO - FAU, donde la queja recurrente son los altos precios de los productos agroecológicos.

Desafortunadamente, hay poca información detallada al respecto. De 21 costos de producción encontrados en la literatura para comparar los resultados de esta investigación, solo cuatro correspondían a productos orgánicos: acelga, espinaca 
(Ávila, 2014), huevos (Borbón, Chaves, y Moreno, 2017) y mermeladas de verduras (Zuleta y Díaz, 2011), pero ninguno correspondía a productos agroecológicos.

Precisamente, la información sobre costos de producción y su análisis se hace más urgente en producción agroecológica, dado que los costos de producción y por derivación, los precios de venta han sido hitos permanentes para asegurar la sostenibilidad de los mercados agroecológicos (Vasco, Palacios, y Paspuel, 2015), que como la FAU, promueven la producción y el consumo sostenibles.

En este contexto, se espera que, al establecer cuáles son los principales componentes en los costos de producción de productos agroecológicos y sus causas, se puedan gestionar los mismos (EAFIT, 2007). De manera que se logre ofertar precios de venta justos, tanto para el productor como para el consumidor. Por esta razón, el objetivo de esta investigación fue analizar los costos de producción de productos agroecológicos obtenidos por productores familiares de pequeña escala, para lo cual se seleccionó una metodología de costeo (Chaparro, 2017), se ajustó según los requerimientos del proyecto, se identificaron los costos de producción de 33 productos, pertenecientes a 15 productores de la FAU, y se analizaron los resultados.

\section{Metodología}

Se realizó una investigación aplicada, bajo un enfoque cuantitativo, con 15 productores de la FAU, y un total de 33 productos. La investigación se realizó en tres fases: en la primera se hizo una revisión de literatura para identificar una metodología de costeo aplicable a productores agroecológicos de pequeña escala. En la segunda fase se aplicó esta metodología con los productores. En la tercera fase se analizaron los resultados y se preparó un informe por productor, un informe consolidado y se socializaron los resultados.

\section{Fase 1. Selección de metodología de costeo}

El cálculo de costos se apoyó en la metodología reportada por Chaparro (2017), quien trabajó con diez familias del proceso Mercados Campesinos, de Cundinamarca, Boyacá, Meta y Tolima. Esta metodología buscaba establecer los costos e ingresos totales de cada sistema de producción, para lo que se apoyó en una estructura de registro que tuvo en cuenta las siguientes variables:

- Costos: relacionados directamente con la producción -monetarios y no monetarios-. 
- Gastos: relacionados exclusivamente al hogar -educación, salud, recreación, servicios públicos, entre otros - sean monetarios y no monetarios.

- Egresos: costos o gastos monetarios.

- Ingresos: entradas monetarias o no monetarias para el bienestar del hogar, la producción y reproducción del sistema.

- Autoabastecimiento: es una parte de los ingresos - no monetarios-, cuyo consumo puede tener lugar en el hogar.

- Trabajo familiar: se refiere al trabajo aportado por los mismos miembros de la familia.

- Excedentes económicos: diferencia - positiva o negativa- entre ingresos menos costos y gastos.

- Excedente monetario: diferencia entre ingresos monetarios menos costos y gastos monetarios.

- Excedente no monetario: diferencia entre ingresos no monetarios - autoabastecimiento- menos costos y gastos no monetarios - mano de obra familiar, insumos obtenidos en el predio-.

El instrumento de recolección de información seleccionado fue aplicado en una prueba piloto para validar su completitud y confiabilidad, antes de proceder a la aplicación con los productores. Después de la prueba piloto se hicieron ajustes para construir la versión definitiva, agregando las siguientes casillas al instrumento de recolección de información, como se pueden ver en el instrumento final, presentado en el anexo 1:

- Costos unitarios: costos por unidad de producto, según su presentación para la venta.

- Costos monetarios: pagados con dinero.

- Costos no monetarios: mano de obra familiar no pagada, insumos obtenidos del predio.

- Autoabastecimiento -ingresos no monetarios-.

- Cantidad vendida -ingresos monetarios-.

- Cantidad no vendida -inventario de producto terminado-.

- Ingresos monetarios: en efectivo.

- Ingresos no monetarios: en especie.

- Ingresos totales: monetarios y no monetarios.

- Rentabilidad monetaria: ingresos monetarios menos costos monetarios. 
- Rentabilidad no monetaria: ingresos no monetarios menos costos no monetarios.

- Rentabilidad económica: Ingresos totales menos costos totales.

- La categoría de gastos no hizo parte de este formato.

\section{Fase 2. Aplicación del instrumento de recolección de información}

Este instrumento de recolección de información se aplicó para cada producto evaluado. Para el desarrollo de esta investigación la muestra final de productos fue de 33 -13 alimentos frescos, 18 alimentos procesados, un producto de aseo personal y una planta ornamental-, y la de productores fue de 15 (ver tabla 1).

Tabla 1. Productos agroecológicos evaluados.

\begin{tabular}{|c|c|c|c|}
\hline \# & Producto & Tipo & Productor \\
\hline 1 & Miel & Alimento fresco agroecológico & Productor 07 \\
\hline 2 & Huevos & Alimento fresco en transición agroecológica & Productor 03 \\
\hline 3 & Arveja & Alimento fresco agroecológico & Productor 05 \\
\hline 4 & Papa & Alimento fresco agroecológico & Productor 05 \\
\hline 5 & Tomate & Alimento fresco agroecológico & Productor 05 \\
\hline 6 & Acelga & Alimento fresco agroecológico & Productor 05 \\
\hline 7 & Cilantro & Alimento fresco agroecológico & Productor 05 \\
\hline 8 & Apio & Alimento fresco agroecológico & Productor 05 \\
\hline 9 & Espinaca & Alimento fresco agroecológico & Productor 05 \\
\hline 10 & Coliflor & Alimento fresco agroecológico & Productor 05 \\
\hline 11 & Lechuga & Alimento fresco agroecológico & Productor 05 \\
\hline 12 & Curuba & Alimento fresco agroecológico & Productor 05 \\
\hline 13 & Polen & Alimento fresco agroecológico & Productor 07 \\
\hline 14 & Mantequilla & Alimento procesado convencional & Productor 11 \\
\hline 15 & Chocolate & Alimento procesado agroecológico & Productor 04 \\
\hline 16 & Mermelada (conserva de frutas) & Alimento procesado agroecológico & Productor 09 \\
\hline 17 & Granola & Alimento procesado en transición agroecológica & Productor 06 \\
\hline 18 & Café & Alimento procesado agroecológico & Productor 02 \\
\hline 19 & Hamburguesa & Alimento procesado en transición agroecológica & Productor 08 \\
\hline 20 & Arepas & Alimento procesado en transición agroecológica & Productor 08 \\
\hline 21 & Vermelada (conserva de verduras) & Alimento procesado agroecológico & Productor 10 \\
\hline 22 & Extracto de noni & Alimento procesado agroecológico & Productor 13 \\
\hline
\end{tabular}


(viene)

\begin{tabular}{llll}
\hline$\#$ & \multicolumn{1}{c}{ Producto } & Tipo & Productor \\
\hline 23 & Pasabocas & Alimento procesado en transición agroecológica & Productor 06 \\
\hline 24 & Sacha inchi & Alimento procesado agroecológico & Productor 01 \\
\hline 25 & Queso & Alimento procesado agroecológico & Productor 02 \\
\hline 26 & Cupcakes & Alimento procesado agroecológico & Productor 09 \\
\hline 27 & Brownie & Alimento procesado en transición agroecológica & Productor 12 \\
\hline 28 & Sal marina con especias & Alimento procesado agroecológico & Productor 11 \\
\hline 29 & Harina de plátano & Alimento procesado agroecológico & Productor 02 \\
\hline 30 & Jengibre & Alimento procesado convencional & Productor 01 \\
\hline 31 & Cúrcuma & Alimento procesado convencional & Productor 01 \\
\hline 32 & Jabón & Aseo - procesado agroecológico & Productor 14 \\
\hline 33 & Suculenta & Planta ornamental agroecológica & Productor 15 \\
\hline
\end{tabular}

Fuente: elaboración propia

Los productos se eligieron teniendo en cuenta los que integran la canasta básica familiar de mayor venta en la FAU, dando prioridad a alimentos, e incluyendo por último productos de vivero - plantas ornamentales, a saber, suculentas - y productos cosméticos y de aseo personal, tratando de abarcar al mayor número de productores y productos, con el fin de tener la mayor representatividad posible de cada categoría ofertada en la FAU. Básicamente se excluyeron los productores de artesanías.

Los productos se consideraron agroecológicos o en transición según el Sistema Participativo de Garantías-SPG de la Red de Mercados Agroecológicos de Bogotá Región-RMABR del que hace parte la FAU'? Un producto se consideró agroecológico si cumplía la definición de agroecología y los 20 principios del SPG, o se consideró en transición agroecológica si cumplía parcialmente esta definición y los principios, y en el caso de los productos procesados, si según el principio 11, por lo menos el 75 \% de los ingredientes eran agroecológicos (Chaparro y Naranjo, 2017). En la fase de análisis de resultados, se consideran comparables los productos agroecológicos y orgánicos, ya que no se encontraron otros estudios reportados en la literatura, que presenten costos de producción discriminados para productos agroecológicos.

\section{Fase 3. Análisis de resultados}

Después de recolectar la información de costos con cada productor, se analizaron los resultados verificando su completitud y precisión, se calculó el costo unitario para

1 Se puede ampliar la información en: http://redmercadosagroecologicosbogota.co/ home/sistema-de-garantias-participativo/ 
cada caso - costo total / unidades producidas en el periodo evaluado- y se comparó con los costos por unidad reportados en la literatura -21 sistemas de producción documentados: cuatro orgánicos, nueve convencionales y ocho no reportan el tipo de producción-. También se comparó con la literatura los resultados de escala de producción y mano de obra.

\section{RESULTADOS Y DISCUSIÓN}

El $80 \%$ de los 15 productores no llevaba registros de producción, el 26 \% no conocía sus costos, y el 73 \% no tenía registros de venta, a pesar de lo cual, se logró recolectar la información necesaria para la investigación. A pesar de esto, el conocimiento de los costos de producción es alto en los productores evaluados, frente a otros reportes de la literatura. En un estudio realizado en Brasil, se puso en evidencia que, en 2010, solo el 44 \% de los productores sabía sus costos y en 2015, el 57 \% (Araujo, 2017). Este mismo estudio recomienda, a nivel de política pública local como una de las prioridades, que se capacite a los productores en gestión de costos.

\section{Escala de producción de los productores participantes}

En la tabla 2 se presenta la escala de producción de cada productor en kilogramos, con el periodo de producción evaluado y el detalle en unidades producidas, según la presentación de cada producto.

Tabla 2. Escala de producción y periodo de análisis por productor.

\begin{tabular}{lcll}
\hline Organización & $\begin{array}{c}\text { Escala de } \\
\text { producción }\end{array}$ & Periodo de análisis & \multicolumn{1}{c}{ Observaciones } \\
\hline Productor 01 & $30 \mathrm{~kg}$ & Primer semestre 2016 & $\begin{array}{l}\text { 300 paquetes de } 100 \mathrm{~g} \text { (nuez), } 48 \text { paquetes } \\
\text { de } 63 \text { g (cúrcuma), } 48 \text { paquetes de } 63 \mathrm{~g} \\
\text { (jengibre) }\end{array}$ \\
\hline Productor 02 & 2.902 kg & Enero a diciembre 2016 & $\begin{array}{l}\text { 224 paquetes de harina de plátano (200 } \\
\text { g), 1.520 paquetes de café (250 g), 2.400 } \\
\text { paquetes de queso g), 2.676 paquetes de } \\
\text { mantequilla especias (240 g), 3.969 paque- } \\
\text { tes de mantequilla ghee (160 g). }\end{array}$ \\
\hline Productor 03 & $1.581 \mathrm{~kg}$ & $\begin{array}{l}\text { 20 agosto 2016 a 19 } \\
\text { agosto 2017 }\end{array}$ & $\begin{array}{l}\text { 38 cubetas tipo A, 513 cubetas tipo AA, 232 } \\
\text { cubetas tipo extra, 20 cubetas tipo Jumbo }\end{array}$ \\
\hline Productor 04 & $16,96 \mathrm{~kg}$ & Marzo a septiembre 2017 & \begin{tabular}{l} 
98 paquetes de chocolate de mesa de 150 g \\
\hline
\end{tabular} \\
\hline
\end{tabular}


(viene)

\begin{tabular}{|c|c|c|c|}
\hline Organización & $\begin{array}{l}\text { Escala de } \\
\text { producción }\end{array}$ & Periodo de análisis & Observaciones \\
\hline Productor 05 & $14.516 \mathrm{~kg}$ & Enero a diciembre 2016 & $\begin{array}{l}104 \text { kg curuba, } 5.200 \text { unidades lechuga, } 624 \\
\text { kg coliflor, } 572 \mathrm{~kg} \text { apio, } 1.144 \text { kg espinaca } \\
624 \mathrm{~kg} \text { acelga, } 208 \mathrm{~kg} \text { cilantro, } 3.680 \mathrm{~kg} \text { to- } \\
\text { mate chonto } 5.000 \mathrm{~kg} \text { papa, } 1.000 \mathrm{~kg} \text { arveja }\end{array}$ \\
\hline \multirow[t]{2}{*}{ Productor 06} & \multirow[t]{2}{*}{$537,75 \mathrm{~kg}$} & \multirow{2}{*}{$\begin{array}{l}5 \text { abril a } 5 \text { septiembre } \\
2017\end{array}$} & $\begin{array}{l}493,25 \mathrm{~kg} \text { granola (presentaciones: 300, 250, } \\
500 \mathrm{~g}) .\end{array}$ \\
\hline & & & 50 kg pasabocas (media libra) \\
\hline Productor 07 & $781,96 \mathrm{~kg}$ & Enero a diciembre 2016 & $\begin{array}{l}588,82 \mathrm{~kg} \text { de miel (presentaciones } 320 \mathrm{~g} \text {, } \\
650 \mathrm{~g}, 500 \mathrm{~g} \text {, propolizada, kg), } 193 \mathrm{~kg} \text { de } \\
\text { polen }\end{array}$ \\
\hline Productor 08 & $770,7 \mathrm{~kg}$ & Enero a diciembre 2016 & $\begin{array}{l}1.050 \text { paquetes arepas ( } 350 \mathrm{~g}), 1.008 \text { paque- } \\
\text { tes hamburguesas ( } 400 \mathrm{~g} \text { ) }\end{array}$ \\
\hline Productor 09 & $61,34 \mathrm{~kg}$ & $\begin{array}{l}\text { Septiembre a noviembre } \\
2017\end{array}$ & $\begin{array}{l}712 \text { unidades cupcake, } 200 \text { unidades mer- } \\
\text { meladas ( } 35 \mathrm{~g}, 110 \mathrm{~g}, 265 \mathrm{~g})\end{array}$ \\
\hline Productor 10 & $1.273,8 \mathrm{~kg}$ & Enero a diciembre 2016 & $\begin{array}{l}120 \text { unidades ( } 30 \mathrm{~g}), 4.200 \text { unidades (125 g), } \\
3240 \text { unidades ( } 230 \mathrm{~g} \text { ) de vermeladas }\end{array}$ \\
\hline Productor 11 & $782 \mathrm{~kg}$ & Enero a diciembre 2016 & $\begin{array}{l}2.600 \text { unidades sal marina con especias } \\
(250 \mathrm{~g}), 264 \mathrm{lb} \text { de mantequilla ghee }\end{array}$ \\
\hline Productor 12 & $20 \mathrm{~kg}$ & Agosto a noviembre 2017 & $\begin{array}{l}90 \text { unidades brownie con agraz, } 160 \text { brow- } \\
\text { nie tradicional con panela }\end{array}$ \\
\hline Productor 13 & $186,48 \mathrm{~kg}$ & Enero a diciembre 2016 & 504 envases (370 ml) de extracto de noni \\
\hline Productor 14 & $36,9 \mathrm{~kg}$ & Enero a septiembre 2017 & 410 unidades de jabón de 90 g cada uno \\
\hline Productor 15 & No Aplica & Año 2016 & 480 unidades de suculentas \\
\hline
\end{tabular}

Fuente: elaboración propia

Del único productor que no se calculó la producción en kilogramos fue del Productor 15 - suculentas ornamentales-, porque no aplicaba. Según la tabla 2, la producción se encuentra en un rango de 16,96 kg para el Productor 04 a $14.516 \mathrm{~kg}$ para el Productor 05, con un promedio de $1.678 \mathrm{~kg}$, para periodos de análisis de entre dos meses - Productor 9- y un año - productores 2, 3, 5, 7, 8, 10, 11, 13 y 15-, con un promedio aproximado de 9,2 meses - promedio total: $182 \mathrm{~kg}$ por mes-.

Haciendo un comparativo con la literatura consultada -21 sistemas de producción: cuatro orgánicos, nueve convencionales y ocho no reportan el tipo de producción- la producción se encuentra en un rango de 141 kg (Sánchez, 2014) a 741.570 kg (Borbón, Chaves, y Moreno, 2017), siendo muy superior a las de este estudio -8,3 a 51 veces-, y dejando en evidencia las bajas escalas de la producción agroecológica y en transición de los productores de la FAU.

No se evaluó si las bajas producciones corresponden solo a bajas escalas de producción o también a menores productividades, que según Crowder y Reganold (2015) y Röös et al., (2018), podrían ser de entre el 10 y el $18 \%$. 


\section{Mano de obra}

En la tabla 3 se encuentra la descripción de la mano de obra que se genera en cada sistema de producción evaluado, junto con observaciones sobre su tiempo de dedicación y algunos aspectos adicionales.

Tabla 3. Generación de mano de obra productores FAU.

\begin{tabular}{lll}
\hline \multicolumn{1}{c}{ Productor } & $\begin{array}{c}\text { Generación de } \\
\text { empleo }\end{array}$ & \multicolumn{1}{c}{ Observación } \\
\hline Productor 01 & 2 personas & Una de tiempo completo y una parcial \\
\hline Productor 02 & 3 personas & De tiempo completo \\
\hline Productor 03 & 4 personas & Dos de tiempo completo y dos parcial \\
\hline Productor 04 & 4 personas & Dos personas de tiempo completo y dos parcial \\
\hline Productor 05 & 23 personas & Una por obra o labor, doce de logística, padre, madre, \\
\hline Productor 06 & 2 internos, 5 personas más \\
\hline Productor 07 & 3 personas & Una de tiempo completo y dos parcial \\
\hline Productor 08 & 4 personas & De tiempo completo \\
\hline Productor 09 & 2 personas & De tiempo completo \\
\hline Productor 10 & 2 personas & Una de tiempo completo y una parcial \\
\hline Productor $11,12,14,15$ & 1 persona & De tiempo completo \\
\hline Productor 13 & 2 personas & De tiempo completo \\
\hline
\end{tabular}

Fuente: elaboración propia

La generación de empleo se encuentra en un total de 55 puestos de trabajo, 33 de ellos de tiempo completo -en su mayoría los emprendedores y sus parejas- y 22 de ellos de tiempo parcial, para un promedio de 3,6 empleos por cada productor, y una moda de 2 empleos, aunque el 26,6 \% de los productores tiene un solo trabajador y una sola organización genera 23 empleos.

La generación de empleo reportada en la literatura - para 18 de estos sistemas de producción - se encuentra en un rango de 1 a 10 personas, con un promedio de 4,2 personas por cada producto evaluado, el 18,75 \% de los productos generan empleo a 3 personas y sólo un producto genera empleo a 10 personas, por lo que, mientras los reportes de la literatura tienen escalas de producción mucho mayores -entre 8,3 y 51 veces-, generan únicamente 0,4 veces el empleo generado por los productores agroecológicos y en transición de la FAU, lo que coincide con otros reportes, que evidencian altos costos de mano de obra en la producción orgánica (FAO, 2019) y costos en mano de obra entre 7 y $13 \%$ superiores en agricultura orgánica frente a la convencional (Crowder y Reganold, 2015). 


\section{Costos unitarios por producto}

Los costos unitarios por producto y su comparación con la literatura se presentan en la tabla 4, incluyendo observaciones a la escala de producción.

Tabla 4. Costo unitario por producto y comparativo con la literatura.

\begin{tabular}{|c|c|c|c|}
\hline Producto & Costo unitario FAU & Costo unitario literatura & Observación \\
\hline Huevos & $\$ 852$ unidad & $\begin{array}{l}\text { \$218 unidad (Borbón, Chaves, y } \\
\text { Moreno, 2017) }\end{array}$ & $\begin{array}{l}\text { El estudio con que se compa- } \\
\text { ra produce } 48,7 \text { veces más. }\end{array}$ \\
\hline Hamburguesa & $\begin{array}{l}\$ 3320 \text { paquete } 5 \text { uni- } \\
\text { dades }\end{array}$ & $\begin{array}{l}\$ 4035 \text { paquete } 5 \text { unidades (Apa- } \\
\text { ricio, Cubides, y Mendoza, 2010) }\end{array}$ & $\begin{array}{l}\text { El estudio con que se compa- } \\
\text { ra produce } 300 \text { veces más. }\end{array}$ \\
\hline Arepas & $\begin{array}{l}\text { \$2 } 656 \text { paquete } 4 \text { uni- } \\
\text { dades }\end{array}$ & $\begin{array}{l}\text { \$3 } 957 \text { paquete } 5 \text { unidades (Estu- } \\
\text { piñán, González, y Huertas, 2017) }\end{array}$ & $\begin{array}{l}\text { El estudio con que se compa- } \\
\text { ra produce } 71,3 \text { veces más. }\end{array}$ \\
\hline Queso & $\$ 6068 \mathrm{lb}$ & $\begin{array}{l}\text { \$3 } 407 \text { lb (Alonso, Morantes, y } \\
\text { López, 2015) }\end{array}$ & $\begin{array}{l}\text { El estudio con que se compa- } \\
\text { ra produce } 16,4 \text { veces más. }\end{array}$ \\
\hline Chocolate & \$15537 paquete $150 \mathrm{~g}$ & $\begin{array}{l}\$ 2723 \text { paquete } 240 \text { g (Prado, } \\
\text { Herrera, y Mantilla, 2017) }\end{array}$ & $\begin{array}{l}\text { El estudio con que se compa- } \\
\text { ra produce } 245 \text { veces más. }\end{array}$ \\
\hline Café & $\$ 5563$ paquete $250 \mathrm{~g}$ & \$4 658 lb (Nieto, 2013) & $\begin{array}{l}\text { El estudio con que se compa- } \\
\text { ra produce } 5,5 \text { veces más. }\end{array}$ \\
\hline $\begin{array}{l}\text { Harina de } \\
\text { plátano }\end{array}$ & $\$ 5943$ paquete $200 \mathrm{~g}$ & No se dispone de información & \\
\hline $\begin{array}{l}\text { Mantequilla } \\
\text { ghee }\end{array}$ & $\$ 3537$ tarro $160 \mathrm{~g}$ & No se dispone información & \\
\hline Granola & $\$ 30728 \mathrm{~kg}$ & No se dispone información & \\
\hline Pasabocas & $\$ 8392$ paquete $250 \mathrm{~g}$ & No se dispone información & \\
\hline Miel & $\$ 11040 \mathrm{~kg}$ & \$13 520 kg (Sánchez A. , 2014) & $\begin{array}{l}\text { El Productor } 07 \text { produce } 1,4 \\
\text { veces más }\end{array}$ \\
\hline Polen & $\$ 33660 \mathrm{~kg}$ & \$13.520 kg (Sánchez A. , 2014) & $\begin{array}{l}\text { El Productor } 07 \text { produce } 1,3 \\
\text { veces más }\end{array}$ \\
\hline Curuba & $\$ 2648 \mathrm{~kg}$ & No se dispone de información & \\
\hline Papa & $\$ 3030 \mathrm{~kg}$ & No se dispone de información & \\
\hline Lechuga & $\$ 3072$ unidad & No se dispone de información & \\
\hline Tomate chonto & $\$ 2994 \mathrm{~kg}$ & $\$ 727$ kg (Alvarez, 2011) & $\begin{array}{l}\text { El estudio con que se compa- } \\
\text { ra produce } 4,6 \text { veces más. }\end{array}$ \\
\hline Arveja & $\$ 3030 \mathrm{~kg}$ & \$5 748 kg (Amaya, 2017) & $\begin{array}{l}\text { El estudio con que se compa- } \\
\text { ra produce } 1.55 \text { veces más. }\end{array}$ \\
\hline Apio & $\$ 1517 \mathrm{~kg}$ & $\$ 4906$ kg (Morimitsu, 2014) & $\begin{array}{l}\text { El Productor } 05 \text { produce 1,07 } \\
\text { veces más. }\end{array}$ \\
\hline Cilantro & $\$ 3045 \mathrm{~kg}$ & $\$ 500$ kg (Balanta, 2017) & $\begin{array}{l}\text { El estudio con que se compa- } \\
\text { ra produce } 81,7 \text { veces más. }\end{array}$ \\
\hline Coliflor & $\$ 3001 \mathrm{~kg}$ & No se dispone de información & \\
\hline Acelga & $\$ 3002 \mathrm{~kg}$ & $\begin{array}{l}\text { \$4 } 588 \text { unidad, peso ND (Ávila, } \\
\text { 2014) }\end{array}$ & El Productor 05 produce 3,3 \\
\hline Espinaca & $\$ 3034 \mathrm{~kg}$ & $\begin{array}{l}\text { \$3 } 823 \text { unidad, peso ND (Ávila, } \\
\text { 2014) }\end{array}$ & veces más \\
\hline
\end{tabular}


(viene)

\begin{tabular}{|c|c|c|c|}
\hline Producto & Costo unitario FAU & Costo unitario literatura & Observación \\
\hline Mermelada & $\$ 4198$ frasco $110 \mathrm{~g}$ & $\begin{array}{l}\$ 2141 \text { frasco } 150 \text { g (Reinoso, } \\
2014 \text { ) }\end{array}$ & $\begin{array}{l}\text { El estudio con que se compa- } \\
\text { ra produce } 8,7 \text { veces más. }\end{array}$ \\
\hline $\begin{array}{l}\text { Extracto de } \\
\text { noni }\end{array}$ & $\$ 22064$ botella $370 \mathrm{ml}$ & $\begin{array}{l}\text { \$19 } 235 \text { botella } 500 \mathrm{ml} \text { (Naranjo, } \\
\text { 2013) }\end{array}$ & $\begin{array}{l}\text { El estudio con que se compa- } \\
\text { ra produce } 168 \text { veces más. }\end{array}$ \\
\hline \multirow[t]{3}{*}{ Brownie } & \multirow[t]{3}{*}{$\$ 2407$ unidad } & $\$ 630$ con nueces dietético & \multirow{3}{*}{$\begin{array}{l}\text { El estudio con que se compa- } \\
\text { ra produce } 68 \text { veces más. }\end{array}$} \\
\hline & & $\$ 599$ con nueces & \\
\hline & & $\begin{array}{l}\text { \$636 con nueces light (Rincón, } \\
\text { 2011) }\end{array}$ & \\
\hline Cupcake & $\$ 4449$ unidad & $\begin{array}{l}\$ 1033 \text { unidad (Barragan y Mo- } \\
\text { rales, 2012) }\end{array}$ & $\begin{array}{l}\text { El estudio con que se compa- } \\
\text { ra produce } 224 \text { veces más. }\end{array}$ \\
\hline \multirow[t]{2}{*}{ Vermelada } & \multirow[t]{2}{*}{$\$ 9589$ frasco $230 \mathrm{~g}$} & \$2 458 ahuyama & \multirow{2}{*}{$\begin{array}{l}\text { El estudio con que se compa- } \\
\text { ra produce } 8,4 \text { veces más. }\end{array}$} \\
\hline & & $\begin{array}{l}\text { \$2 } 333 \text { calabaza envase } 250 \mathrm{~g} \\
\text { (Zuleta y Díaz, 2011) }\end{array}$ & \\
\hline $\begin{array}{l}\text { Sal con } \\
\text { especias }\end{array}$ & $\$ 2463$ paquete $250 \mathrm{~g}$ & No se dispone de información & \\
\hline Suculentas & $\$ 9799$ unidad & \$15 953 unidad (Posada, 2017) & $\begin{array}{l}\text { Flora, Cloro y fila produce } 1,6 \\
\text { veces más. }\end{array}$ \\
\hline Jabón & $\$ 11435$ unidad $90 \mathrm{~g}$ & $\begin{array}{l}\$ 1487 \text { unidad } 130 \mathrm{~g} \text { (Montes y } \\
\text { Duque, 2013) }\end{array}$ & $\begin{array}{l}\text { El estudio con que se compa- } \\
\text { ra produce } 219,5 \text { veces más. }\end{array}$ \\
\hline
\end{tabular}

Fuente: elaboración propia

De los 33 productos evaluados, se excluyeron 3 productos de los que la información recolectada no es confiable para el cálculo de costos unitarios -cúrcuma, inchi y jengibre-.

A partir de la tabla 4 se puede concluir que solo en seis de los 21 productos de los que se dispone información de la literatura para comparar, los productos de la FAU cuentan con una mayor escala de producción -rango 1,07 a 3,3 veces más y promedio 1,7 veces más-, mientras en los 15 productos restantes (71\%), las escalas de producción son entre 1,55 veces más - arveja-y 300 veces más - hamburguesas-, con un promedio de 98 veces más producción, que los productores de la FAU. Estos resultados evidencian que la producción agroecológica o en transición de la FAU es mayoritariamente de muy baja escala.

El $62 \%$ (13) de los 21 productos de la FAU evaluados, de los que se dispone de información en la literatura para comparar, tienen costos unitarios más altos - huevos, queso, chocolate, café, polen, tomate chonto, cilantro, mermelada, extracto de noni, brownie, cupcakes, mermeladas de verduras, jabón-, mientras el 38 \% tiene costos unitarios más bajos - hamburguesa, arepa, miel, arveja, apio, acelga, espinaca, suculentas-. Para uno de los 33 productos el análisis comparativo de costos unitarios no es concluyente - suculentas-, pues los dos productos no son del todo comparables, al ser productos que combinan agricultura y arte. 
En el caso de las hamburguesas y las arepas, sorprende que los costos unitarios sean más bajos, dado que estos productos están en transición agroecológica y que los estudios con los que se compara son de producción convencional y producen 300 y 71,3 veces más que el productor de la FAU, por lo que la única explicación es que el costo de los ingredientes y la mano de obra del Productor 08 son muy bajos, lo cual puede generar una baja remuneración de la mano de obra de este emprendimiento en transición agroecológica, similar a lo reportado en otros estudios (Chaparro y Calle, 2017), práctica común de la producción campesina y familiar para ser resilientes (Lopera, 1999).

En los casos de miel, arveja, apio, acelga y espinaca, el primer producto agroecológico y los demás orgánicos, no se esperaba que tuvieran costos inferiores a los de la literatura, aunque pueden deberse a la escala de producción.

Para comprender mejor las razones de los altos costos de producción unitarios de 15 productos de la FAU, se presenta el costo de mayor proporción para cada producto en la tabla 5.

Tabla 5. Costo unitario por producto frente al costo de mayor proporción.

\begin{tabular}{|c|c|c|}
\hline Producto & Costo unitario FAU & Costo de mayor proporción \\
\hline \multirow{2}{*}{ Huevos } & \multirow{2}{*}{$\$ 852$ unidad } & Mano de obra $50 \%$ \\
\hline & & Insumos $28 \%$ \\
\hline Hamburguesa & $\$ 3320$ paquete 5 unidades & Insumos $58 \%$ \\
\hline Arepas & \$2 656 paquete 4 unidades & Mano de obra $28 \%$ \\
\hline \multirow{2}{*}{ Queso } & \multirow{2}{*}{$\$ 6068 \mathrm{lb}$} & Mano de obra $48 \%$ \\
\hline & & Insumos $40 \%$ \\
\hline \multirow{2}{*}{ Chocolate } & \multirow{2}{*}{ \$15 537 paquete $150 \mathrm{~g}$} & Servicios $42 \%$ \\
\hline & & Insumos $33 \%$ \\
\hline \multirow{2}{*}{ Café } & \multirow{2}{*}{$\$ 5563$ paquete $250 \mathrm{~g}$} & Insumos $61 \%$ \\
\hline & & Costos de venta $22 \%$ \\
\hline \multirow{2}{*}{ Harina de plátano } & \multirow{2}{*}{$\$ 5943$ paquete $200 \mathrm{~g}$} & Mano de obra $59 \%$ \\
\hline & & Insumos $32 \%$ \\
\hline \multirow{2}{*}{ Mantequilla ghee } & \multirow{2}{*}{$\$ 3537$ tarro $160 \mathrm{~g}$} & Insumos $37 \%$ \\
\hline & & Mano de obra $29 \%$ \\
\hline \multirow{2}{*}{ Granola } & \multirow{2}{*}{$\$ 30728 \mathrm{~kg}$} & Insumos $45 \%$ \\
\hline & & Mano de obra $18 \%$ \\
\hline \multirow{2}{*}{ Pasabocas } & \multirow{2}{*}{$\$ 8392$ paquete $250 \mathrm{~g}$} & Insumos $58 \%$ \\
\hline & & Servicios $19 \%$ \\
\hline Miel & $\$ 11040 \mathrm{~kg}$ & Mano de obra $73 \%$ \\
\hline Polen & $\$ 33660 \mathrm{~kg}$ & Costos de venta $18 \%$ \\
\hline
\end{tabular}


(viene)

\begin{tabular}{|c|c|c|}
\hline Producto & Costo unitario FAU & Costo de mayor proporción \\
\hline Curuba & $\$ 2648 \mathrm{~kg}$ & \multirow{10}{*}{$\begin{array}{l}\text { Insumos } 61 \% \\
\text { Mano de obra } 30 \%\end{array}$} \\
\hline Papa & $\$ 3030$ kg & \\
\hline Lechuga & $\$ 3072$ unidad & \\
\hline Tomate chonto & $\$ 2994$ kg & \\
\hline Arveja & $\$ 3030 \mathrm{~kg}$ & \\
\hline Apio & $\$ 1517 \mathrm{~kg}$ & \\
\hline Cilantro & $\$ 3045 \mathrm{~kg}$ & \\
\hline Coliflor & $\$ 3001 \mathrm{~kg}$ & \\
\hline Acelga & $\$ 3002$ kg & \\
\hline Espinaca & $\$ 3034 \mathrm{~kg}$ & \\
\hline \multirow{2}{*}{ Mermelada } & \multirow{2}{*}{$\$ 4198$ frasco $110 \mathrm{~g}$} & Costos de venta $43 \%$ \\
\hline & & Mano de obra $26 \%$ \\
\hline \multirow{2}{*}{ Extracto de noni } & \multirow{2}{*}{$\$ 22064$ botella $370 \mathrm{ml}$} & Mano de obra $61 \%$ \\
\hline & & Costos de venta $17 \%$ \\
\hline \multirow{2}{*}{ Brownie } & \multirow{2}{*}{$\$ 2407$ unidad } & Insumos $39 \%$ \\
\hline & & Mano de obra $24 \%$ \\
\hline \multirow{2}{*}{ Cupcake } & \multirow{2}{*}{$\$ 4449$ unidad } & Mano de obra $58 \%$ \\
\hline & & Costos de inversión 23 \% \\
\hline \multirow{2}{*}{ Vermelada } & \multirow{2}{*}{$\$ 9589$ frasco $230 \mathrm{~g}$} & Costos de venta $42 \%$ \\
\hline & & Mano de obra $32 \%$ \\
\hline \multirow{2}{*}{ Sal con especias } & \multirow{2}{*}{$\$ 2463$ paquete $250 \mathrm{~g}$} & Mano de obra $33 \%$ \\
\hline & & Insumos $33 \%$ \\
\hline \multirow{2}{*}{ Suculentas } & \multirow{2}{*}{$\$ 9799$ unidad } & Mano de obra $56 \%$ \\
\hline & & Costos de venta $32 \%$ \\
\hline \multirow{2}{*}{ Jabón } & \multirow{2}{*}{$\$ 11435$ unidad $90 \mathrm{~g}$} & Insumos $41 \%$ \\
\hline & & Servicios $27 \%$ \\
\hline
\end{tabular}

Fuente: elaboración propia

Para el 60 \% (18) de 30 productos evaluados - se omiten cúrcuma, jengibre y sacha inchi- el principal costo de producción son los insumos. La explicación en 8 de estos 18 casos, es que los productos son procesados - café, jabón, hamburguesas, mantequilla, granola, pasabocas, brownies, arepas-, y, por tanto, los ingredientes agroecológicos o en transición, o comprados en baja escala, son más costosos, aun cuando solo dos de estos productos son agroecológicos y seis están en transición agroecológica. En los diez productos restantes, siendo frescos, se esperaba que el mayor costo de producción fuera la mano de obra, pero no es así, y se podría deber a que el Productor 05 tiene una gran demanda por el mercado, lo que lo hace requerir de un gran volumen de insumos para mantener la producción sin afectar el suelo del predio por la constante extracción de nutrientes. 
Para el 26,6 \% (8) de 30 productos evaluados, el principal costo de producción es la mano de obra - suculentas, extracto de noni, miel, polen, harina de plátano, queso, huevos, cupcakes-, lo cual se explica con facilidad en los primeros siete productos, porque todos o la gran mayoría de los insumos provienen de los predios de los mismos productores.

En un caso, sal con especias, tanto los insumos como la mano de obra corresponden a un 33 \% de los costos de producción, lo cual se explica en la gran proporción de especias de este producto, que son producidas y procesadas por el mismo productor, mientras la sal marina es comprada a un tercero.

En dos casos (6,6 \%) el principal costo de producción son los costos de ventas -mermeladas de frutas y verduras-, lo que se explica por los bajos volúmenes de ventas -al no ser un producto esencial en la canasta familiar-, lo que genera que los costos de venta tengan un gran peso en los costos totales.

En un solo caso - chocolate-, el principal costo de producción son los servicios (3,3 \%) debido al transporte - de Huila a Bogotá, aproximadamente $415 \mathrm{~km}$ - y al arriendo donde se procesa, para una producción de muy pequeña escala.

En general, para los productos orgánicos y agroecológicos, los costos de producción son más altos, dado que la exclusión de insumos de síntesis química -fertilizantes y pesticidas-, determinan un incremento en el uso de mano de obra, pero adicionalmente porque los insumos orgánicos son costosos (Sánchez, 2014), (Crowder y Reganold, 2015).

Precisamente, el estudio de Araujo (2017) reporta costos de producción 30 \% superiores en café orgánico frente a café convencional, principalmente por la mano de obra -frente a la mecanización parcial o completa en café convencional- y el transporte de fertilizantes. Resultados similares reportan Chaparro y Calle (2017), con costos de producción agroecológica fuertemente relacionados a la mano de obra y a la dependencia o no por insumos externos.

Los altos costos de producción y precios de venta en productos orgánicos son también reportados en Ecuador, desde donde proponen subsidios para insumos y transporte, así como asistencia técnica, tecnologías adaptadas al medio y financiamiento con bajos intereses para superarlos (Vasco, Palacios, y Paspuel, 2015).

Es de resaltar que, en algunos casos, las prácticas agroecológicas han apoyado la reducción de costos de producción, que en este estudio se reportan en solo ocho de 21 productos evaluados con información comparativa disponible -miel, arveja, apio, acelga, espinaca, hamburguesas, arepas, suculentas-, como lo hace el estudio de Chaparro y Calle (2017) en sistemas de producción campesina y de pequeña escala. 


\section{Utilidad o pérdida del sistema de producción}

El análisis de los costos de producción unitarios no es suficiente, ya que un productor puede tener costos unitarios bajos y tener pérdidas, o tener costos unitarios altos y tener utilidades, por esta razón, en la tabla 6 se presenta la utilidad o pérdida para cada producto.

Tabla 6. Utilidad o pérdida de cada producto evaluado.

\begin{tabular}{|c|c|c|c|}
\hline Organización & $\begin{array}{l}\text { Escala de } \\
\text { producción }\end{array}$ & Periodo de análisis & Utilidad/Pérdida por producto \\
\hline \multirow{5}{*}{ Productor 02} & \multirow{5}{*}{$2.902 \mathrm{~kg}$} & \multirow{5}{*}{ Año 2016} & Café \$6 743013 \\
\hline & & & Queso \$14 237599 \\
\hline & & & Mantequilla ghee $\$ \mathbf{1 7} 713993$ \\
\hline & & & Mantequilla con especias $\$ 19475493$ \\
\hline & & & Harina de plátano $\$ \mathbf{6 8 4} 6 \mathbf{6 3 3}$ \\
\hline Productor 03 & $1.581 \mathrm{~kg}$ & 20 agosto 2016 a 19 agosto 2017 & Huevo -7 874705 \\
\hline Productor 04 & $16,96 \mathrm{~kg}$ & Marzo a septiembre 2017 & Chocolate $\mathbf{- \$ 8 3 6 . 7 0 4}$ \\
\hline \multirow{9}{*}{ Productor 05} & \multirow{9}{*}{$14.516 \mathrm{~kg}$} & \multirow{9}{*}{ Año 2016} & Papa \$11 599813 \\
\hline & & & Apio $\$ 1410614$ \\
\hline & & & Tomate chonto \$8 $\mathbf{8 5 3} \mathbf{6 8 2}$ \\
\hline & & & Cilantro \$2 112047 \\
\hline & & & Arveja \$4 469963 \\
\hline & & & Coliflor \$1 496486 \\
\hline & & & Lechuga -\$5 836562 \\
\hline & & & Curuba $\$ \mathbf{1 7 6} 943$ \\
\hline & & & Espinaca y acelga \$1 $\mathbf{4 1 0} \mathbf{6 1 4}$ \\
\hline \multirow{2}{*}{ Productor 06} & \multirow{2}{*}{$537,75 \mathrm{~kg}$} & \multirow{2}{*}{5 abril a 5 septiembre 2017} & Granola $\$ 1.721 .560$ \\
\hline & & & Pasabocas \$841.621 \\
\hline Productor 07 & $781,96 \mathrm{~kg}$ & Año 2016 & Miel y polen $\mathbf{\$ 7 . 4 4 8 . 1 4 7}$ \\
\hline \multirow{2}{*}{ Productor 08} & \multirow{2}{*}{$770,7 \mathrm{~kg}$} & \multirow{2}{*}{ Año 2016} & Hamburguesa \$1 693812 \\
\hline & & & Arepas \$1 411510 \\
\hline \multirow{2}{*}{ Productor 09} & \multirow{2}{*}{$61,34 \mathrm{~kg}$} & \multirow{2}{*}{ Septiembre a noviembre 2017} & Mermelada \$10 498 \\
\hline & & & Cupcake $\mathbf{- \$ 4 3 5 9 8 5}$ \\
\hline Productor 10 & $1.273,8 \mathrm{~kg}$ & Año 2016 & Vermelada \$30 649978 \\
\hline \multirow{2}{*}{ Productor 11} & \multirow{2}{*}{$782 \mathrm{~kg}$} & \multirow{2}{*}{ Año 2016} & Sal con especias \$5 295131 \\
\hline & & & Mantequilla ghee $\$ 394245$ \\
\hline Productor 12 & $20 \mathrm{~kg}$ & Agosto a noviembre 2017 & Brownie -\$56 845 \\
\hline Productor 13 & $186,48 \mathrm{~kg}$ & Año 2016 & Extracto de noni -\$1 $161 \mathbf{2 7 5}$ \\
\hline Productor 14 & $36,9 \mathrm{~kg}$ & Enero a septiembre 2017 & Jabón -\$383461 \\
\hline Productor 15 & No aplica & Año 2016 & Suculentas \$1 056081 \\
\hline
\end{tabular}

Fuente: elaboración propia 
En la tabla 6 no se incluyeron los datos del Productor 01, dado que no son confiables - cúrcuma, jengibre y sacha inchi-. De los 30 productos plasmados en la tabla 6, 23 productos generaron utilidad, y 7 productos tuvieron pérdida así:

\section{Productos que generaron utilidades:}

\section{Hamburguesas y arepas (Productor 08)}

Hamburguesas en transición agroecológica²: generó una utilidad de \$1 693812 en 2016, a pesar de que su producción es de baja escala frente a otros casos. El estudio de Aparicio, Cubides y Mendoza (2010), presenta los costos de un sucedáneo de carne de hamburguesa convencional con una utilidad de \$189 489 238, debido a que cuenta con una producción 300 veces superior en comparación con la de Productor 08 y a que sus precios son superiores (\$7 000 precio pleno y $\$ 6300$ precio promocional, mientras que el Productor 08 vende el paquete de 5 unidades por \$5 000).

Arepas en transición agroecológica: generó una utilidad de \$1 411510 en 2016. Teniendo en cuenta el análisis comparativo con la literatura, se concluye que a pesar de que Productor 08 tiene una pequeña escala de producción, logra un costo de producción total 182,3 veces menor comparado con el costo de producción del estudio de Estupiñán, Gonzáles y Huertas (2017), además de esto, el estudio presenta una escala de producción 71,3 veces superior a la de Productor 08, obteniendo ganancias de \$53 112 204. Hay que aclarar que las arepas del estudio comparativo son convencionales.

La estrategia de Productor 08 es lograr costos unitarios de producción bajos, para ofertar precios de venta igualmente bajos, a pesar de tener una baja escala de producción y bajos costos no monetarios.

\section{Café, queso y harina de plátano agroecológicos}

Café: generó utilidades de \$6 743013 en 2016 con este producto³. Debido a su baja escala de producción, ya que produce un $18 \%$ de la cantidad que produce el estudio reportado por Nieto (2013), su costo de producción es 2,39 veces el costo de producción del estudio consultado y su precio de venta es 1,74 veces el del estudio consultado, si bien hay que tener en cuenta el año de cada estudio y que el café comparado es convencional. La estrategia de este productor ha sido ofertar un alto precio

\footnotetext{
2 Ver nota al pie de página número 8 para ampliar la información.
}

3 Ver nota al pie de página número 8 para ampliar la información. 
de venta, a pesar de contar con costos unitarios de producción altos y con volúmenes de venta bajos, teniendo costos no monetarios del $64 \%$ de los costos totales.

Queso agroecológico: generó utilidades de \$14 237599 en 2016, mientras el proyecto de Alonso, Morantes y López (2015), con una gran escala de producción, generó una utilidad de \$28 243 630. La razón de la diferencia es que, aunque Productor 02 tiene un precio de venta más alto en un $62 \%$, su escala de producción corresponde apenas al $6 \%$ de la producción del proyecto de queso convencional. La estrategia de este productor es tener costos no monetarios altos $-42 \%$ de los costos totales-.

Harina de plátano: generó una utilidad de \$684 633 con este producto en el año 2016. No se encontró literatura para hacer el análisis comparativo. La estrategia de este productor es tener costos no monetarios del $52 \%$ de los costos totales.

\section{Miel y polen agroecológicos}

El Productor 07 obtuvo una utilidad de \$7 448147 con estos dos productos en 2016, lo que puede deberse a que su escala producción es superior a la producción reportada por Sánchez (2014), gracias a lo cual su precio de venta es inferior, incluso siendo un producto agroecológico. Hay que resaltar que la remuneración de la mano de obra se hace después de obtener las utilidades en el estudio consultado, mientras que el Productor 07 ya tiene en cuenta la mano de obra en sus costos. La estrategia de este productor es tener bajos costos de producción (miel) y una escala de producción media, de manera que ofrecen precios de venta medios, teniendo en cuenta que el Productor 07 genera utilidades altas teniendo unos costos no monetarios del $67 \%$ de los costos totales para este producto.

\section{Sal con especias, mantequilla ghee}

Sal con especias agroecológica: generó una utilidad de \$5 295131 con este producto en 2016. No se realizó ningún análisis comparativo dado que no se encontró información al respecto en la literatura. La estrategia de este productor es venderlo a un alto precio y tener altos costos no monetarios $-33 \%$ de los costos totales-.

Mantequilla ghee: para este producto se tomaron los datos de dos organizaciones. El Productor 11 genera una utilidad de \$394 245, y el Productor 02 genera una utilidad de \$17 713 993. Para hacer un análisis entre estos dos productos se tomó como referencia de peso un kilogramo, mientras el Productor 11 produjo 132 kilogramos de mantequilla ghee, el Productor 02 produjo 635 kilogramos en el mismo periodo (2016), por lo cual, tanto los costos $-2,4$ veces - como los ingresos $-5,13$ 
veces - son más altos para el Productor 02 -agroecológico- que para el Productor 11 -transición agroecológica-. La estrategia de este productor es el alto precio de venta, pues tiene altos costos unitarios, una baja escala de producción, y costos no monetarios del $29 \%$ de los costos totales.

\section{Mermelada agroecológica}

Generó una mínima utilidad de \$10 498 que corresponde al punto de equilibrio. El proyecto de Reinoso (2014) registra costos de producción en 2014 de \$14,27 por gramo de mermelada, frente a \$71,42, \$36,36 y \$30,18 por gramo de mermelada del Productor 09 para las presentaciones de 35 gr, 110 gr y 265 gr respectivamente. Esta diferencia en precios se debe al año de cada estudio, a la calidad agroecológica del producto de este estudio y a la escala de producción de cada proyecto. La estrategia de este productor es tener un bajo precio de venta, a pesar de tener unos altos costos unitarios de producción y una baja escala de producción, además de tener costos no monetarios del $19 \%$ de los costos totales.

\section{Granola y pasabocas en transición agroecológica}

Granola: generó una utilidad de \$1 721 560, entre abril y septiembre de 2017, lo que quiere decir que la utilidad por mes es de $\$ 344$ 312, que es aceptable para la escala de producción. No se dispone de literatura para comparar estos datos. La estrategia de este productor es tener un precio de venta alto, pues los costos unitarios de producción son altos y la escala de producción es baja.

Pasabocas: generó una utilidad, entre abril y septiembre de 2017, de \$841 621. No se dispone de literatura para comparar los datos.

\section{Vermelada}

El Productor 10 obtuvo una utilidad de \$30 649978 por este producto para el año 2016, lo que quiere decir que la utilidad por mes es de \$2 554 165, que es buena para la escala de producción y para ser un emprendimiento familiar. Mientras la producción del Productor 10 es de 1 273,8 kg, la del estudio de Zuleta y Díaz (2011) es de $10800 \mathrm{~kg}$, con un 748 \% de diferencia, debido a lo cual, los precios de venta son altos -el Productor 10 ofrece la presentación de 230 gramos a \$12 000 y el estudio una presentación de 250 gramos a \$5 000, un $261 \%$ de diferencia-, aun cuando se debe ser precavido por el año de reporte de la información de cada proyecto. Cabe resaltar 
que el producto del Productor 10 es agroecológico mientras el de Zuleta y Díaz es orgánico. La estrategia de este producto es el alto precio de venta, pues tiene altos costos unitarios de producción, una alta escala de producción y no tiene costos no monetarios.

\section{Hortalizas}

Apio obtuvo una utilidad de \$1 410614 en el año 2016. Los costos por libra registrados por Morimitsu (2014) -no especifican si es orgánico o convencional- son 3,23 veces más altos, y los precios de venta son 1,27 veces más altos en comparación con los del Productor 05, aun a pesar de que la producción del Productor 05 es similar (7 \% superior) y que los datos de Morimitsu son de dos años atrás.

Tomate chonto obtuvo una utilidad de \$8 853682 en el año 2016. En el estudio de Álvarez (2011), en donde no se especifica si el tomate es orgánico o convencional, la escala de producción es 462 \% más alta que la del Productor 05, por lo que el costo de producción y el precio de venta son muy bajos, lo que genera una menor utilidad de \$2 928151.

Cilantro obtuvo una utilidad de \$2 112047 en el año 2016. El estudio de Balanta (2017), en el que no se especifica si el cilantro es orgánico o convencional, presenta una producción 81,7 veces mayor a la del Productor 05, por ende, sus ganancias son más altas con un valor de \$15 375 097, a pesar de su precio más bajo.

Arveja obtuvo una utilidad de \$4 469963 en el año 2016. El estudio de Amaya (2017), en el que no se especifica si la arveja es orgánica o convencional, tiene una producción 1,55 veces más alta y el precio de venta es un 10 \% más alto que el Productor 05, a pesar de lo cual, sus costos son 2,94 veces más altos y no alcanzan dejar utilidad, dejando una pérdida de -\$3692300.

Espinaca y acelga obtuvieron una utilidad de \$1 410614 en 2016. En el estudio de Ávila (2014), con valores proyectados, la escala de producción corresponde a un $61 \%$ de la del Productor 05, por lo que sus costos de producción son superiores y los de venta son mucho más altos, a pesar del año de la referencia.

Para papa, coliflor y curuba, no se encontró literatura para hacer el análisis comparativo. La estrategia de estos productos frescos es tener un alto precio de venta y altos costos no monetarios, aunque cuatro de nueve productos frescos evaluados tienen bajos costos unitarios y tres de nueve tienen alta escala de producción, comparativamente.

Adicional a estos productos mencionados en la tabla 6, se analizaron los costos de las suculentas. 


\section{Suculentas}

Flora, Cloro y fila, obtuvo una utilidad de \$1 056081 en el periodo de estudio. Para este análisis se tomó el producto del Productor 15 ofertado en recipiente de cristal - una sola planta-, mientras el estudio consultado vende suculentas tipo terrarios varias plantas-. Flora, Cloro y fila producen más y vende a un precio más económico en comparación a Posada (2017), aún a pesar de que su producto es agroecológico. La estrategia de este producto es tener un bajo costo unitario de producción, una escala de producción alta, un precio de venta alto y altos costos no monetarios.

\section{Productos que generaron pérdidas}

\section{Huevos en transición agroecológica}

Este producto generó una pérdida no monetaria de -\$7874 705, pues el número de gallinas es pequeño, y la mano de obra es costosa. De otro lado, los costos no monetarios son mayores a los costos monetarios, lo que genera la incorrecta percepción de que el sistema de producción es rentable, esto se explica porque, en el imaginario del productor, la depreciación, la mano de obra familiar y los insumos obtenidos del predio - no monetarios-, no son "costos", lo cual es común en economía campesina (Lopera, 1999).

El estudio de Borbón, Chaves y Moreno (2017), con un producto orgánico, presenta costos de producción correspondientes al 26 \% de los costos de producción del Productor 03, lo que se explica en una mayor escala de producción -1 177 096,34 huevos, calculada, no explícita en la publicación-. Las deficiencias del Productor 03 son un alto costo unitario de producción, bajos costos no monetarios, una baja escala de producción y precios de venta bajos, siendo el principal, la escala.

\section{Chocolate agroecológico}

El Productor 04 obtuvo pérdidas de -\$836 $704-74 \%$ monetaria y 26 \% no monetaria-, dado que la producción del periodo no compensa el cacao que se compró - produjo solo 98 paquetes de 150 gramos con 90 kilogramos de cacao, cuando debió producir cerca de 600-. La producción es de tan baja escala, que el costo de cada paquete es muy alto y los ingresos obtenidos no alcanzan a cubrir los costos.

Teniendo en cuenta el análisis comparativo con la literatura, en el estudio de Prado, Herrera y Mantilla (2017), la producción es tan grande (24 000 paquetes de 240 gramos) que el costo (9,15 veces) y el precio (12\%) de cada paquete son más bajos 
que en el Productor 04, dejando una utilidad de \$47 840 787. Las deficiencias del Productor 04 son tener un alto costo unitario de producción, bajos costos no monetarios, baja escala de producción y precios de venta altos, siendo el principal, la escala.

\section{Extracto de noni agroecológico}

El Productor 13 tuvo una pérdida no monetaria de -\$1 161275 con este producto en 2016, esto se debe a que el número de botellas que se produjo es bajo y los ingresos obtenidos no alcanzaron a cubrir los costos.

Teniendo en cuenta el análisis comparativo con la literatura, el estudio de Naranjo (2013) produjo 24192 botellas y el Productor 13 solo produjo el 2 \% de esta cantidad, el precio de venta del Productor 13 corresponde a un $89 \%$ del precio del otro producto, aun cuando es precio 2016 y producto agroecológico, mientras el del jugo de noni de Naranjo es del 2013 y no es agroecológico. Las deficiencias del Productor 13 son un alto costo unitario de producción, baja escala de producción y precios de venta bajos, a pesar de tener altos costos no monetarios, siendo la principal, la escala.

\section{Brownie en transición agroecológica}

El Productor 12 tuvo una pérdida no monetaria de -\$56 845 con este producto, generada en un periodo de tres meses, debido a que la producción es a muy pequeña escala, lo que genera que el precio de venta deba ser muy alto para generar ganancias, a pesar de lo cual los ingresos obtenidos no alcanzan a cubrir los costos. El estudio de Rincón (2011) genera una utilidad de \$28 072 309, teniendo un costo de producción total 60,5 veces superior al del Productor 12 y un precio de venta $28 \%$ inferior, la diferencia entre los dos proyectos se debe a que la escala de producción del Productor 12 es del 1,5 \% de la de Rincón (2011). Las deficiencias del Productor 12 son un alto costo unitario de producción, bajos costos no monetarios, baja escala de producción y precio de venta alto, siendo la principal, la escala.

\section{Lechuga orgánica}

El Productor 05 obtuvo una pérdida monetaria de -\$5836 562 con este producto en 2016, dado que el costo de producción es 1,5 veces mayor al precio de venta. Teniendo en cuenta el análisis comparativo con la literatura, el Productor 05 sobrepasa los costos de la Cámara de Comercio de Bogotá (2015) en 3,25 veces, posiblemente por la escala de producción. Las deficiencias son un alto costo unitario de producción, a pesar de que la escala de producción, los costos no monetarios y el precio de venta son altos. 


\section{Cupcakes agroecológicos}

El Productor 09 obtuvo una pérdida de -\$435 985 - 51\% no monetaria y $49 \%$ monetaria-, en un periodo de tres meses, dado que la producción es muy pequeña, lo que deriva en un costo unitario muy alto, y los ingresos no alcanzan a cubrir los costos. El estudio de Barragán y Morales (2012) con su producto convencional, presenta costos 52,9 veces más altos, producción 56,2 veces mayor, y precio de venta 5,8 veces más alto que su costo de producción, para una utilidad de \$114 576.000. Las deficiencias del Productor 09 son un alto costo unitario, bajos costos no monetarios y baja escala de producción, a pesar de tener un alto precio de venta.

\section{Jabón agroecológico}

El Productor 14 obtuvo una pérdida de -\$383461 con este producto, la producción es de baja escala y el costo de cada jabón es muy alto, por lo que los ingresos obtenidos no alcanzan a cubrir los costos, aunque no está descontado el inventario de insumos. Teniendo en cuenta el análisis comparativo con la literatura, el estudio de Montes y Duque (2013) con su producto convencional, presenta precios muy por debajo de los del Productor 14, lo cual se explica en la escala de producción y en la calidad de los ingredientes, pero también en el año del estudio (2013). Las deficiencias del productor son un alto costo unitario, bajos costos no monetarios y baja escala de producción, a pesar de tener un alto precio de venta.

Para el grupo de productos que generaron utilidades a sus productores, las estrategias más comunes fueron tener altos precios de venta (19/23) y altos costos no monetarios (14/23). En el primer caso se generan dificultades para los compradores, dado que los precios son una razón frecuente de no compra, como se ha identificado en otros estudios (Rödiger y Hamm, 2015). En el segundo caso, es positivo si el productor otorga resiliencia a su actividad económica, al dar flexibilidad a sus costos, pero puede ser negativo con el tiempo al no reponer dichos costos naturales -insumos obtenidos en el predio- o sociales - remuneración de la mano de obra(Chaparro y Calle, 2017).

Para el grupo de productos que generaron pérdidas, las principales deficiencias en respectivo orden fueron: tener costos unitarios de producción altos, bajas escalas de producción y bajos costos no monetarios, como reportan igualmente Chaparro y Calle (2017).

Es importante resaltar que de 14 productores evaluados con datos confiables, siete (P02, P05, P06, P07, P08, P10, P11) tienen utilidades importantes que les permite ser sostenibles y permanecer en su actividad económica como reportan otros 
proyectos agroecológicos (Fernandes dos santos, Stradiotto, Araújo, y Matias, 2014), cinco de ellos son agroecológicos y dos de ellos tienen producción en transición agroecológica, lo que es determinante en sus sostenibilidad, como lo reportan Chaparro y Calle (2017).

Otro aspecto favorable para estos productores es que la FAU es un circuito corto de comercialización, lo que permite que el 100 \% del precio pagado por los consumidores llegue a los productores, a diferencia de lo que ocurre en mercados convencionales con intermediarios (Caicedo, 2013). Hay que resaltar que las utilidades recibidas por los productores agroecológicos o en transición no son muy altas, comparativamente con las de productores convencionales, a pesar de lo cual los productores persisten, lo que se explica en que estas formas de economía solidaria no toman sus decisiones basadas únicamente el criterio monetario, sino que son multicriteriales y abarcan también aspectos sociales y ambientales (Marañón, 2016).

\section{Conclusiones}

El $80 \%$ de los 15 productores no llevaba registros de producción, el 26 \% no conocía sus costos, y el 73 \% no tenía registros de venta, lo cual determinó una mayor inversión de tiempo en el desarrollo de la investigación.

La producción de 15 productores de la FAU se encuentra en un rango de 16,96 $\mathrm{kg}$ a $14.516 \mathrm{~kg}$, con un promedio de $1.678 \mathrm{~kg}$, para periodos de análisis de entre dos meses y un año - promedio $182 \mathrm{~kg}$ por mes-, correspondiendo a entre el 2 y $12 \%$ de la reportada en la literatura - se comparó con otros 21 sistemas de producción: cuatro orgánicos, nueve convencionales y ocho no reportan el tipo de producción-.

Los 15 productores de la FAU generan entre 1 a 23 empleos, con una moda de dos empleos, evidenciando una mayor generación de empleo frente a otros sistemas de producción, por lo que, mientras los reportes de la literatura tienen escalas de producción mucho mayores -entre 8,3 y 51 veces-, generan únicamente 0,4 veces el empleo generado por los productores agroecológicos y en transición de la FAU.

Los costos unitarios de producción son más altos en un $62 \%$ de los productos de la FAU evaluados, frente a sistemas de producción reportados en la literatura.

En el 60 \% (18) de 30 productos evaluados el principal costo de producción son los insumos, ya sea porque son procesados y sus ingredientes son costosos (44\%) o porque son frescos (55\%) y tienen una gran dependencia por insumos externos. Para el 26,6 \% (8), el principal costo de producción es la mano de obra, debido, principalmente, a que todos o la gran mayoría de los insumos provienen de los predios de los mismos productores. 
En el $76,6 \%$ de 30 productos evaluados se obtuvo utilidad, debido principalmente a que los productores tienen altos precios de venta (83\%) y altos costos no monetarios (61 \%). En el 23,3 \% de 30 productos evaluados, no se obtuvo utilidad, debido principalmente a tener costos unitarios de producción altos, bajas escalas de producción y bajos costos no monetarios.

De 14 productores evaluados con datos confiables, 7 tienen utilidades importantes que les permite ser sostenibles y permanecer en su actividad económica, cinco de ellos son agroecológicos y dos están en transición.

\section{Recomendaciones para productores:}

- Llevar registros de producción y ventas, tanto técnicos como contables.

- Identificar la escala mínima de producción, la productividad mínima, el costo y el precio que harían viable en proyecto, antes de su ejecución.

- Hacer investigación de mercados de manera permanente, para conocer los costos de producción y los precios de venta de productos orgánicos y convencionales.

- Identificar soluciones tecnológicas o de otra índole que permitan incrementar la escala de producción de productos agroecológicos, para reducir sus costos y precios de venta, asegurando ingresos dignos a los productores y precios justos a los compradores, sin perder el concepto agroecológico.

- Asegurar una producción continua y a mediana escala, para favorecer el abastecimiento de materias primas a los procesadores.

- Reducir la dependencia por insumos externos.

\section{Recomendaciones para siguientes investigaciones:}

- Incluir la variable de productividad, además de la de escala y costos de producción en los análisis.

- Incluir inventarios de insumos en los análisis, en los casos de productos procesados.

\section{Recomendaciones para proyectos de emprendimiento y desarrollo territorial:}

- Se debe promover la evaluación integral de los proyectos productivos agroecológicos previo a su desarrollo, y en la dimensión económica se 
debe dar especial atención a variables como la escala de producción, la dependencia por insumos externos y su costo, el costo de mano de obra, el autoabastecimiento, la obtención de insumos de los mismos predios de los productores y la productividad.

\section{Referencias}

Aguilar, F. F. (2017). Reseña sobre el estado actual de la agroecología en Cuba. Agroecología; Murcia Tomo 12(1) 7-18.

Alonso, N., Morantes, N., y López, M. (2015). Propuesta para la planeación de la producción y distribución para la industria belemita de lácteos ibel. Recuperado de https://repository. javeriana.edu.co/bitstream/handle/10554/18951/AlonsoValenciaNormaFernanda2015. pdf? sequence=1\&isAllowed=y

Altieri, M. A. (2009). Agroecology, Small Farms, and Food Sovereignty. Monthly Review; New York Tomo 61(3), Jul/Aug. doi:10.14452/MR-061-03-2009-07_8, 102-113.

Alvarez, J. (2011). Plan de negocios para el desarrollo de un proyecto productivo de tomate chonto (lycopersiconesculentumMil) bajo invernadero en la finca de las mercedes municipio de Gomez Plata. Recuperado de http://repository.lasallista.edu.co/dspace/bitstream/10567 /577/1/PLAN\%20DE\%20NEGOCIOS\%20PARA\%20EL\%20DESARROLLO\%20DE\%20UN\%20 PROYECTO\%2OPRODUCTIVO\%20DE\%20TOMATE\%20CHONTO.pdf

Amaya, D. (2017). Establecimiento de un proyecto productivo de arveja (pisum sativum L.) en un area de 5.000 m2 como alternativa económica ante la deforestación en el municipio de ragonvalia, norte de santander. Recuperado de http://repository.lasalle.edu.co/bitstream/handle/10185/24962/46132008_2017.pdf?sequence=1\&isAllowed=y

Aparicio, P., Cubides, Y., y Mendoza, y. (2010). Estudio de factibilidad para la realización de hamburguesas a base de gluten de trigo en la localidad de Kennedy. Recuperado de http://repository. unad.edu.co:8080/bitstream/10596/1679/1/2010-21T-10.pdf

Araujo, M. (2017). Política nacional de agroecología y producción orgánica: productores de café en el sur de Minas Gerais-Brasil. Tesis doctoral. Valencia: Universidad de Valencia.

Aschemann, J., y Zielke, S. (2015). Can't Buy Me Green? A Review of Consumer Perceptions of and Behavior Toward the Price of organic food. Recuperado de https://onlinelibrary.wiley.com/ doi/abs/10.1111/joca.12092 
Ávila, Y. (2014). Creación de un modelo de costos para la línea de hortalizas órganicas en la fundación de mujeres empresarias Marie Poussepin. Recuperado de https://repository.javeriana.edu. co:8443/bitstream/handle/10554/14836/AvilaMartinezYuryCarolina2014.pdf?sequence=1

Balanta, S. (2017). Implementación de un sistema productivo de cilantro (coriandrum sativum) variedad unapal precoso como modelo sostenible de producción agrícola en el corregimiento de Rozo, Palmira, Valle del Cauca. Recuperado de http://repository.lasalle.edu.co/bitstream/ handle/10185/21320/46132075_2017.pdf?sequence=1

Barragan, J., y Morales, L. (2012). De Raca Mandaca Cupcakes. Recuperado de http://repository. ean.edu.co/bitstream/handle/10882/3304/MoralesLina2012.pdf?sequence=6\&isAllowed=y

Borbón, S., Chaves, L., y Moreno, D. (2017). Plan de negocios huevos orgánicos. Recuperado de http://repository.usta.edu.co/bitstream/handle/11634/9478/BorbónSandy2017.pdf? sequence=1\&isAllowed=y

Caicedo, J. (2013). La intermediación como un impedimento al desarrollo del pequeño productor de Medellín. Recuperado de http://www.scielo.org.co/pdf/ccta/v14n1/v14n1a04.pdf

Camara de comercio de Bogotá. (2015). Manual Lechuga. Recuperado de https://www.ccb.org.co/ content/download/13923/176629/file/Lechuga.pdf

Chaparro, A. (2017). Sostenibilidad de la agricultura campesina. Cómo evaluarla y promoverla. Segunda edición. Bogotá: UNIMINUTO y Ediciones de la U.

Chaparro, A., and Calle, A. (2017). Peasant Economy Sustainability in Peasant Markets, Colombia. Journal Agroecology and Sustainable Food Systems, 41, 204-225.

Chaparro, A., y Naranjo, S. (2017). Sistema Participativo de Garantías de la Red de Mercados Agroecológicos de Bogotá Región. Bogotá: Red de Mercados Agroecológicos de Bogotá Región.

Crowder, D., and Reganold, J. (2015). Financial competitiveness of organic agriculture on a global scale. PNAS, 112(24), 7611-7616.

Dankers, C. (2004). Las normas sociales y ambientales, la certificación y el etiquetado de cultivos comerciales. Roma: FAO. 
EAFIT. (2007). La importancia de conocer y saber clasificar los costos para una buena toma de decisiones. Recuperado de www.eafit.edu.co/escuelas/administracion/consultorio-contable/ Documents/boletines/costos-presupuesto/b11.pdf

Estupiñán, D., González, D., y Huertas, M. (2017). Estudio de viabilidad para la producción y comercialización de arepas de maíz con soya, quinua y queso enriquecidas con fibra en la ciudad de bogotá. Recuperado de http://repository.ucatolica.edu.co/bitstream/10983/15456/1/ ESTUDIO\%20DE\%20VIABILIDAD\%20AREPAS\%20DE\%20MAIZ\%20CON\%20SOYA\%2C\%20 QUINUA\%20Y\%20QUESO\%20EN\%20LA\%20CIUDAD\%20DE\%20BOGOTA..pdf

FAO. (2018). FAO'S work on agroecology. A pathway to achieving the SDGs. Roma: FAO.

FAO. (2019). Organic agriculture. Recuperado de http://www.fao.org/organicag/oa-faq/oafaq5/es/

Fernandes dos santos, C., Stradiotto, E., Araújo, I., and Matias, Z. (2014). Agroecology as a means of sustainability for family-based agriculture. Recuperado de http://www.scielo.br/scielo. php?pid=S1414-753X2014000200004\&script=sci_arttext\&tlng=en

FIBL e IFOAM - Organics International. (2019). The world of organic agriculture. Statistics and emerging trends 2019. Suiza: IFOAM. Recuperado de http://www.organic-world.net/yearbook/ yearbook-2017.html

Lopera, J. (1999). Lecturas sobre economía campesina y desarrollo tecnológico. Bogotá: Corpoica.

Marañón, B. (2016). De la crisis estructural del patrón de poder mundial, colonial, moderno y capitalista hacia la solidaridad económica y los buenos vivires en América Latina. Cooperativismo \& Desarrollo, 24(109). doi: https://doi.org/10.16925/co.v24i109.1500, 9-26.

Marian, L., Chrysochou, P., Krystallis, A., and Thøgersen, J. (2014). The role of price as a product attribute in the organic food context: an exploration based on actual purchase data. Food quality and preference, 37., 52-60.

Martínez, C. (2016). Consumo de alimentos orgánicos en Colombia: una cultura incipiente. Tesis. Cajicá: Universidad Militar Nueva Granada. Especialización en Alta Gerencia. Facultad de ciencias económicas. Recuperado de https://repository.unimilitar.edu.co/ bitstream/handle/10654/14424/Mart\%EDnezCardozoC\%E9sarAndr\%E9s2016.pdf;jsessio nid=63D53562B737B83156317D2B1DC9B7BC?sequence=3 
Martínez-Torres, M., y Rosset, P. (2014). Diálogo de saberes in La Vía Campesina: food sovereignty and agroecology. The Journal of Peasant Studies, 41(6). doi: https://doi-org.ezproxy.uniminuto.edu/10.1080/03066150.2013.872632, 979-997.

Montes, D., y Duque, I. (2013). Estudio de factibilidad para el montaje y puesta en marcha de una empresa fabricadora de jabones exfoliantes a base de café para el cuidado de la piel (Frutos de mi tierra) en el municipio de Mistrato, Risaralda. Recuperado de http://repositorio.utp.edu. co/dspace/bitstream/handle/11059/3926/6581186132M779.pdf;sequence=1

Morimitsu, K. (2014). Creación de una empresa manufacturera y comercializadora de verduras (cebolla cabezona, pimentón, apio y zanahoria) empacadas al vacio en diferentes cortes para el mercado colombiano de negocios dedicados a la comida rápida, iniciando con la introducción. Recuperado de https://repository.javeriana.edu.co/bitstream/handle/10554/10673/ MorimitsuOspinaKenjiRamiro2014.pdf?sequence=1\&isAllowed=y

Naranjo, R. (2013). Proyecto de factibilidad para la creación de una empresa productora y comercializadora de extracto de noni para el sector sur de la ciudad de Quito. Recuperado de http:// dspace.unl.edu.ec/jspui/bitstream/123456789/6255/1/R\%C3\%B3mulo\%20Fernando\%20 Naranjo\%20Esp\%C3\%ADn.pdf

Nieto, E. (2013). Plan de negocio para la creación de una empresa productora y comercializadora de café. Recuperado de http://repository.ean.edu.co/bitstream/handle/10882/5112/ NietoErika2013.pdf?sequence=3

Posada, J. (2017). Plan de marketing para la empresa suculento terrario. Bogotá: Universidad Piloto de Colombia Facultad de Ingeniería Especialización Gerencia de Mercadeo Estratégico. Recuperado de http://polux.unipiloto.edu.co:8080/00003853.pdf

Prado, A., Herrera, C., y Mantilla, L. (2017). Estudio de prefactibilidad para el montaje de una fábrica de chocolate en el municipio de Rivera, Huila. Recuperado de http://repository.ucatolica.edu. co/bitstream/10983/15463/1/Trabajo\%20de\%20Grado\%20Final\%20cacao.pdf

Raigón, D. (2008). Alimentos ecológicos, calidad y salud. Andalucía: Junta de Andalucía y SEAE.

Reinoso, R. (2014). Estudio de factibilidad para la creación de una pequeña empresa productora y comercializadora de mermelada de uvilla ubicada en el cantón Cotacachi, provincia de Imbabura. Recuperado de http://repositorio.utn.edu.ec/bitstream/123456789/3160/1/02\%20ICO\%20 366\%20TESIS.pdf 
Rincón, C. (2011). Plan de engocios para la creación de la empresa pastelería innovación casera LTDA, destinada a la producción y comercialización de productos de pasteleria y reposteria en la localidad de Chapinero de la ciudad de Bogotá D.C. Recuperado de http://repository.lasalle.edu.co/bitstream/handle/10185/4032/T11.11\%20R471p.pdf?sequence=1\&isAllowed=y

Rödiger, M., and Hamm, U. (2015). How are organic food prices affecting consumer behaviour? A review. Food Quality and Preference, 43, 10-20.

Röös, E., Mie, A., Wivstad, M., Salomon, E., Johansson, B., Gunnarsson, S., and Watson, C. (2018). Risks and opportunities of increasing yields in organic farming. A review. Agronomy for Sustainable Development, 38(14). doi: 10.1007\%2Fs13593-018-0489-3, 1-21.

Sánchez, A. (2014). Sistemas de producción y economía apícola en los departamentos de Cundinamarca y Boyacá. Caso de tres organizaciones de productores. Bogotá: Universidad Nacional de Colombia Facultad de ciencias agrarias. Recuperado de http://www.bdigital. unal.edu.co/46818/1/07790793.2014.pdf

Sánchez, J. (2014). Análisis agroecológico comparado entre las normativas europeas y norteamericanas sobre fitosanitarios, y de sus consecuencias en Latinoamérica. Tesis doctoral. Córdoba: Universidad de Córdoba.

Uribe, L., Fonseca, Z., López, H., and Ayala, D. (2014). Situación alimentaria y nutricional en Colombia bajo el enfoque de determinantes sociales. Boletín 001/2014. . Bogotá: OSAN, MAPS, FAO. .

Vargas, R. (2008). La investigación aplicada: una forma de conocer las realidades con evidencia científica. Recuperado de https://revistas.ucr.ac.cr/index.php/educacion/article/viewFile/538/589

Vasco, C., Palacios, G., y Paspuel, S. (2015). Determinantes socioeconómicos del consumo de productos ecológicos en Quito. Siembra 2, 023-028.

Zuleta, L., y Díaz, C. (2011). Plan de empresa para una productora de mermelada a base de verduras. Recuperado de http://repository.lasalle.edu.co/bitstream/handle/10185/5454/ T12.11;jsessionid=87A68BE3CBA7C9DD3A3870E19FA39B73? sequence=1 
Anexo 1. Formato aplicado para calcular los costos de producción

\begin{tabular}{|c|c|c|c|c|c|}
\hline \multicolumn{2}{|l|}{ Fecha: } & \multicolumn{4}{|c|}{$\begin{array}{l}\text { Tipo sistema de producción Agrícola (Ag) Pecuario (Pe) } \\
\text { Procesamiento (Pr): }\end{array}$} \\
\hline \multirow{2}{*}{$\begin{array}{l}\text { Nombre sistema de producción: } \\
\text { Item }\end{array}$} & \multirow{2}{*}{$\begin{array}{l}\begin{array}{l}\text { Periodo } \\
\text { análisis: }\end{array} \\
\text { Unidad }\end{array}$} & \multirow{2}{*}{$\begin{array}{l}\text { Escala } \\
\text { producción: } \\
\text { Cantidad }\end{array}$} & \multirow{2}{*}{$\begin{array}{c}\begin{array}{c}\text { Datos contacto } \\
\text { sistema de } \\
\text { producción: }\end{array} \\
\begin{array}{c}\text { Costo/Precio } \\
\text { unitario }\end{array}\end{array}$} & \multicolumn{2}{|c|}{ Datos productor: } \\
\hline & & & & $\begin{array}{l}\text { Costo/Precio } \\
\text { total }\end{array}$ & $\%$ \\
\hline \multicolumn{6}{|l|}{ I. Costos variables } \\
\hline \multicolumn{6}{|l|}{ 1.1. Mano de obra } \\
\hline Subtotal mano de obra & & & & & $\%$ \\
\hline \multicolumn{6}{|l|}{ 1.2. Insumos } \\
\hline Subtotal insumos & & & & & $\%$ \\
\hline \multicolumn{6}{|l|}{ 1.3. Costos de venta } \\
\hline Subtotal costos de venta & & & & & $\%$ \\
\hline Subtotal costos variables & & & & & $\%$ \\
\hline II. Costos fijos & & & & & $\%$ \\
\hline \multicolumn{6}{|l|}{ 2.1. Servicios } \\
\hline Subtotal servicios & & & & & $\%$ \\
\hline Subtotal costos fijos & & & & & $\%$ \\
\hline III. Inversiones - Depreciación & & & & & $\%$ \\
\hline Subtotal inversiones - Depreciación & & & & & $\%$ \\
\hline Costos totales & & & & & $\%$ \\
\hline Costos monetarios & & & & & $\%$ \\
\hline Costos no monetarios & & & & & $\%$ \\
\hline \multicolumn{6}{|l|}{ Costo unitario producto 1} \\
\hline \multicolumn{6}{|l|}{ Costo unitario producto 2} \\
\hline \multicolumn{6}{|l|}{ Costo unitario producto $\mathrm{n}$} \\
\hline \multicolumn{6}{|l|}{ I. Ingresos } \\
\hline 1. Producto 1 & & & & & $\%$ \\
\hline 1.1. Autoabastecimiento & & & & & $\%$ \\
\hline 1.2. Venta & & & & & $\%$ \\
\hline 2. Producto 2 & & & & & $\%$ \\
\hline 2.1. Autoabastecimiento & & & & & $\%$ \\
\hline 2.2. Venta & & & & & $\%$ \\
\hline 3. Producto $n$ & & & & & $\%$ \\
\hline 3.1. Autoabastecimiento & & & & & $\%$ \\
\hline 3.2. Venta & & & & & $\%$ \\
\hline Ingresos totales & & & & & $\%$ \\
\hline Ingresos monetarios & & & & & $\%$ \\
\hline Ingresos no monetarios & & & & & $\%$ \\
\hline \multicolumn{6}{|l|}{ Rentabilidad monetaria } \\
\hline \multicolumn{6}{|l|}{ Rentabilidad no monetaria } \\
\hline Rentabilidad económica & & & & & \\
\hline
\end{tabular}

Fuente: elaboración propia 